\title{
Prognosis of Patients with Acute Coronary Syndromes and Bleeding-The Importance of Routine Use of a Bleeding Risk Score
}

\author{
Alexandre de Matos Soeiro*, Ricardo Cesar Campos Devezae Silva, Aline Siqueira Bossa, \\ Cindel Nogueira Zullino, Tatiana de Carvalho Andreucci Torres Leal, \\ Maria Carolina Feres de Almeida Soeiro, Carlos V. Serrano Jr., Múcio Tavares Oliveira Jr. \\ Emergency Unit-Heart Institute, University of São Paulo Medical School, São Paulo, Brazil \\ Email: *alexandre.soeiro@bol.com.br
}

Received 21 October 2015; accepted 1 December 2015; published 4 December 2015

Copyright (C) 2015 by authors and Scientific Research Publishing Inc.

This work is licensed under the Creative Commons Attribution International License (CC BY). http://creativecommons.org/licenses/by/4.0/

(c) (i) Open Access

\begin{abstract}
Introduction: Recent studies showed relation between mortality and bleeding in acute coronary syndromes. Objective: The objective is to analyze the prognosis of patients with acute coronary syndromes with or without in-hospital major and/or minor bleedings. Methods: This was a prospective data bank analysis study with 546 patients (39 with bleeding (group I) and 507 without bleeding (group II)) with acute coronary syndromes included between May 2010 and May 2013. Besides, Mehran bleeding risk score was calculated to all patients. The primary endpoint was all causes of in-hospital death and combined events. Comparison between groups was made by Anova and Q-square. Multivariate analysis was determined by logistic regression and was considered significant when $p<0.05$. Long-term mortality and combined events were studied using Kaplan-meyer curves. Results: The median Mehran bleeding risk score was 18.78 and 15.11 in groups I and II, respectively. Major bleeding was observed in 4.4\%. Significant difference was observed between groups I and II in deaths $(20.5 \%$ vs $2.6 \%, p=0.005)$ and combined events $(35.9 \%$ vs $11.4 \%, p<0.001)$. The same results were observed in multivariate and long-term analysis. Conclusions: Almost half of patients with acute coronary syndromes had higher risk of bleeding, and that with major or minor bleedings had greater deaths and combined events.
\end{abstract}

\section{Keywords}

Unstable Angina, Bleeding, Acute Myocardial Infarction

\footnotetext{
${ }^{*}$ Corresponding author.
}

How to cite this paper: de Matos Soeiro, A., et al. (2015) Prognosis of Patients with Acute Coronary Syndromes and Bleeding-The Importance of Routine Use of a Bleeding Risk Score. World Journal of Cardiovascular Diseases, 5, 327-334. 


\section{Introduction}

The treatment of acute coronary syndromes (ACS) has been focused in reducing ischemic events and restoration of adequate coronary blood flow by using dual antiplatelet therapy, anticoagulation and early revascularization [1] [2]. Combined antithrombotic therapy could improve significant reduction in cardiovascular events but it's associated with higher incidence of bleeding, limiting its universal use in ACS [3] [4]. Bleeding is the most common non-ischemic complication in ACS [3] [4].

Recent studies have been showed direct relationship between bleeding and mortality in patients with ACS [5][10], something that improves the emergence of different scores identifies higher risk patients to that [11] [12]. There is an important association between bleeding and death/MACE. Major bleeding is associated with four times higher risk of death, five times higher risk of reinfarction and 3 times higher risk of stroke. The need of suspension of antiplatelet/anticoagulation medications increases the risk of ischemic events, mainly stent thrombosis [5]-[10].

The real impact of this complication is unknown and not established in Brazilian population.

The objective of this study was to evaluate the utilization of bleeding scores in Brazilian population with ACS and if the intrahospitalar bleeding was related with worse prognosis in a tertiary center.

\section{Methods}

\subsection{Study Population}

This was an observational retrospective data bank analysis study performed in a tertiary health center with 546 patients with ACS included between May 2010 and May 2013. All patients were diagnosed and treated according the AHA/ESC Task Force guidelines [13] [14].

The decision regarding the vascular access was made by hemodinamicist experience and according by patient characteristics. There were not exclusion criteria.

Patients were followed during the hospitalization and after the discharge. They were divided in two groups: with bleedings (group I: $\mathrm{n}=39$ ) and; without bleeding (group II: $\mathrm{n}=507$ ).

The primary outcome was all cause mortality. The secondary outcome was major adverse cardiac events (MACE) included all causes of death, non-fatal unstable angina or AMI/target vessel revascularization, Killip III/IV classification and stroke. The calculated bleeding score was associated with the real occurrence of bleedings.

The study was approved by the ethics and research committee and in all cases was obtained informed consent by patient or a family member.

\subsection{Analytical Methods}

The following data were obtained: age, sex, diabetes, systemic arterial hypertension, smoke, dyslipidemia, previous coronary artery disease (percutaneous coronary intervention or coronary artery bypass graft), hemoglobin, creatinine, higher troponin, left ventricle ejection fraction (Simpson's method) and medication used at hospital (first 24 hours) (Table 1$)$.

Blood was sampled immediately after admission prior to administration of medications (baseline) and daily according by institution protocol. Cardiac markers like troponin-I was measured using standard clinical chemistry. Laboratory upper limits of normal were $0.04 \mathrm{ng} / \mathrm{ml}\left(99^{\mathrm{TH}}\right.$ percentile) for troponin-I measured by Elecsys 2010 (Siemens Healthcare Diagnostics Inc., United States of America) $4^{\text {th }}$ generation immunoassay.

Bleeding score was calculated in all patients using Mehran [11] score at admission. Major bleeding was defined using BARC [15] score types 3 and 5 and minor bleedings types 1 and 2. Post-operative bleedings were not considered. Bleedings were described in Figure 1.

\subsection{Statistical Analysis}

Descriptive analysis of data collected included median, minimum and maximum values. Comparison between groups was made by Anova and Q-square. If Komolgorov-Smirnov tests confirmed normal distribution, continuous variables were summarized using mean \pm standard deviation and were compared using the student t-test for independent samples. The Mann-Whitney U test was used to compare continuous variables if they were not 
Table 1. Baseline characteristics of patients with and without bleedings during in-hospital stay.

\begin{tabular}{|c|c|c|c|}
\hline & Bleeding+ & Bleeding-- & $p$ \\
\hline Age & $62.21 \pm 12.68$ & $62.78 \pm 11.92$ & 0.78 \\
\hline Male (\%) & $56.40 \%$ & $60.40 \%$ & 0.37 \\
\hline Diabetes Mellitus (\%) & $33 \%$ & $39.40 \%$ & 0.71 \\
\hline Hypertension (\%) & $71.80 \%$ & $81.30 \%$ & 0.11 \\
\hline Smoke (\%) & $43.60 \%$ & $41.40 \%$ & 0.46 \\
\hline FH of CAD (\%) & $12.80 \%$ & $12.40 \%$ & 0.55 \\
\hline Dyislipidemia (\%) & $35.90 \%$ & $47.70 \%$ & 0.1 \\
\hline Stable angina (\%) & $5.10 \%$ & $13.00 \%$ & 0.34 \\
\hline Heart failure (\%) & $5.10 \%$ & $7.70 \%$ & 0.56 \\
\hline Previous AMI (\%) & $43.60 \%$ & $37.70 \%$ & 0.29 \\
\hline Previous CABG (\%) & $10.30 \%$ & $16.00 \%$ & 0.24 \\
\hline Previous PCI (\%) & $25.60 \%$ & $25.40 \%$ & 0.55 \\
\hline SAP (mmHg) & $133.41 \pm 30.94$ & $132.74 \pm 28.51$ & 0.89 \\
\hline $\mathrm{Hb}$ (g/dL) (median) & $13.1 \pm 2.69$ & $13.84 \pm 1.88$ & 0.02 \\
\hline $\mathrm{Cr}$ (mg/dL) (median) & $1.51 \pm 1.57$ & $1.29 \pm 0.83$ & 0.14 \\
\hline Troponin (higher/median) (ng/dL) & $5.46 \pm 9.96$ & $6.31 \pm 34.95$ & 0.88 \\
\hline EF (\%) (median) & $47.97 \pm 18.74$ & $39.52 \pm 24.42$ & 0.04 \\
\hline AAS (\%) & $94.90 \%$ & $95.90 \%$ & 0.9 \\
\hline B-blockerr (\%) & $61.50 \%$ & $69 \%$ & 0.6 \\
\hline Enoxaparin (\%) & $56.40 \%$ & $71.60 \%$ & 0.03 \\
\hline GPI IIb/IIIa (\%) & $17.90 \%$ & $11.80 \%$ & 0.26 \\
\hline Clopidogrel (\%) & $82.10 \%$ & $57.80 \%$ & 0.003 \\
\hline ACE inhibitor (\%) & $38.50 \%$ & $50.10 \%$ & 0.11 \\
\hline Statin (\%) & $69.20 \%$ & $81.90 \%$ & 0.04 \\
\hline
\end{tabular}

Legend: $\mathrm{FH}=$ familial history; $\mathrm{CAD}=$ coronary artery disease; $\mathrm{AMI}=$ acute myocardial infarction; $\mathrm{CABG}=$ coronary artery bypass grafting; $\mathrm{PCI}=$ percutaneous coronary intervention; $\mathrm{SAP}=$ systolic arterial pressure; $\mathrm{Hb}=$ hemoglobin; $\mathrm{Cr}=$ creatinine; $\mathrm{EF}=$ ejection fraction; GPI = glycoprotein inhibitor; ACE = angiotensin-converting-enzyme.

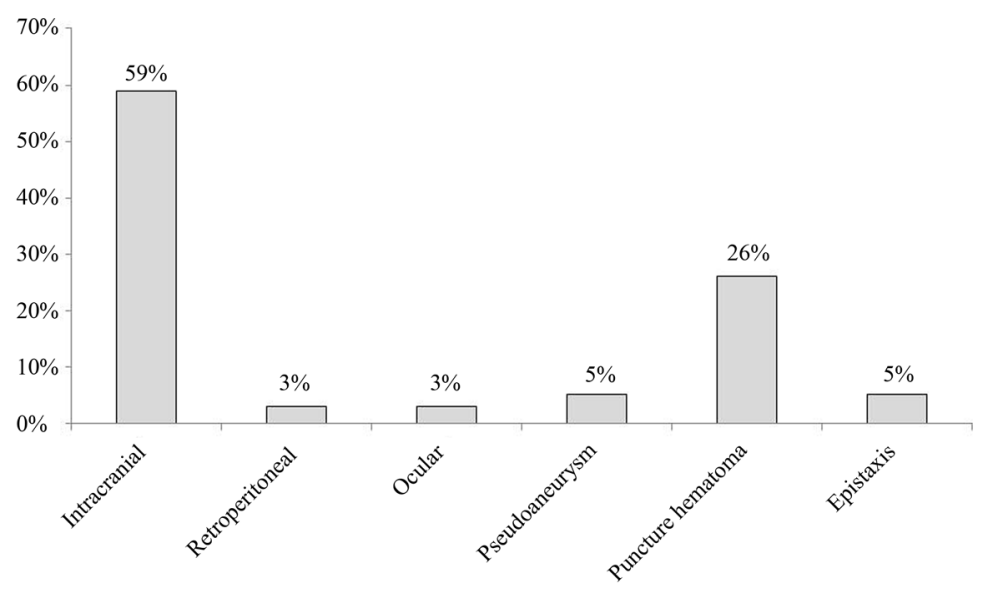

Figure 1. Bleedings found in patients with ACS. 
normally distributed.

Multivariate analysis were determined by logistic regression and was considered significant when $p<0.05$. The variables included all baseline characteristics as showed in Table 1.

Correlation between medium bleeding score and outcomes was determined by Error bar/student t-test.

Long-term analysis of mortality and MACE was made including 546 patients (75.3\%) using Log Rank with a medium follow-up of 10.4 months (1 - 13 months). Data collection was made using telephonic contact and medical records.

All statistical procedures were performed using the Statistical software SPSS v10.0.

\section{Results}

The median age was 62 years old and about 59\% were male patients. The most prevalent risk factor was hypertension (71\% in group I and $81 \%$ in group II) followed by tabagism. Were observed significant differences in hemoglobin ( $13.1 \mathrm{vs} 13.8 \mathrm{mg} / \mathrm{dL}, p=0.02)$, left ventricle ejection fraction $(47.9 \%$ vs $39.5 \%, p=0.04)$, use of enoxaparin ( $56.4 \%$ vs $71.6 \%, p=0.03)$, use of clopidogrel $(82.1 \%$ vs $57.8 \%, p=0.003)$ and use of statin $(69.2 \%$ vs $81.9 \%, 0.04)$, respectively between groups I and II.

Ninety-seven (17.8\%) were ST-elevation myocardial infarction (STEMI) and 449 (82.2\%) were non-ST elevation myocardial infarction (NSTEMI). The median Mehran score in group I and II were, respectively, 18.78 and 15.11 ( $p=0.03$ ). 47.4\% of patients were classified as higher risk of bleeding. Major bleedings were $4.4 \%$ and the most prevalent was intracranial hemorrhage. In $92 \%$ was obtained femoral vascular access and $8 \%$ radial access. Univariate analysis showed relationship between major bleedings and mortality ( $20.5 \%$ vs $2.6 \%, p=$ $0.005)$ and MACE (35.9\% vs $11.4 \%, p<0.001)$ (Table 2).

Multivariate analysis was showed in Table 3 and described a relationship between bleedings and mortality $(\mathrm{OR}=7.87, p=0.005)$ and $\mathrm{MACE}(\mathrm{OR}=4.55, p=0.03)$.

Results of correlation between mortality/MACE according Mehran score were showed in Figure 2. There were relationship between median Mehran score and mortality $(p<0.001)$ but not with MACE $(p=0.92)$.

Long-term results were presented in Figure 3. There were differences in mortality $(23.1 \%$ vs $7.1 \%, p<$ $0.0001)$ and MACE (48.7\% vs $38.1 \%, p=0.009)$ between patients with or without bleedings.

\section{Discussion}

Major finding of this study affirm data of worldwide literature, showing that intra-hospital bleedings in patients with ACS were related with higher mortality and MACE, even in the Brazilian population. About $61 \%$ of that was major bleedings, deducing seriousness.

Table 2. Results of univariate analysis of in-hospital outcomes.

\begin{tabular}{cccc}
\hline & Bleeding+ & Bleeding- & \multicolumn{1}{c}{${ }^{+}$} \\
\hline Reinfarction & $0.0 \%$ & $1.4 \%$ & 0.99 \\
Killip III/IV & $15.4 \%$ & $6.5 \%$ & 0.45 \\
Stroke & $0.0 \%$ & $0.9 \%$ & 0.9 \\
Mortality & $20.5 \%$ & $2.6 \%$ & 0.005 \\
MACE & $35.9 \%$ & $11.4 \%$ & $<0.001$ \\
\hline
\end{tabular}

Legend: MACE = major adverse cardiac events.

Table 3. Results of multivariate analysis of in-hospital outcomes comparing groups I and II.

\begin{tabular}{cccc}
\hline & OR & CI (95\%) & $p$ \\
\hline Killip III/IV & 0.64 & $0.19-2.05$ & 0.45 \\
Mortality & 7.87 & $4.66-9.13$ & 0.005 \\
MACE & 4.55 & $3.57-6.20$ & 0.03 \\
\hline
\end{tabular}

Legend: $\mathrm{CI}$ = confidence interval; MACE = major adverse cardiac events. 

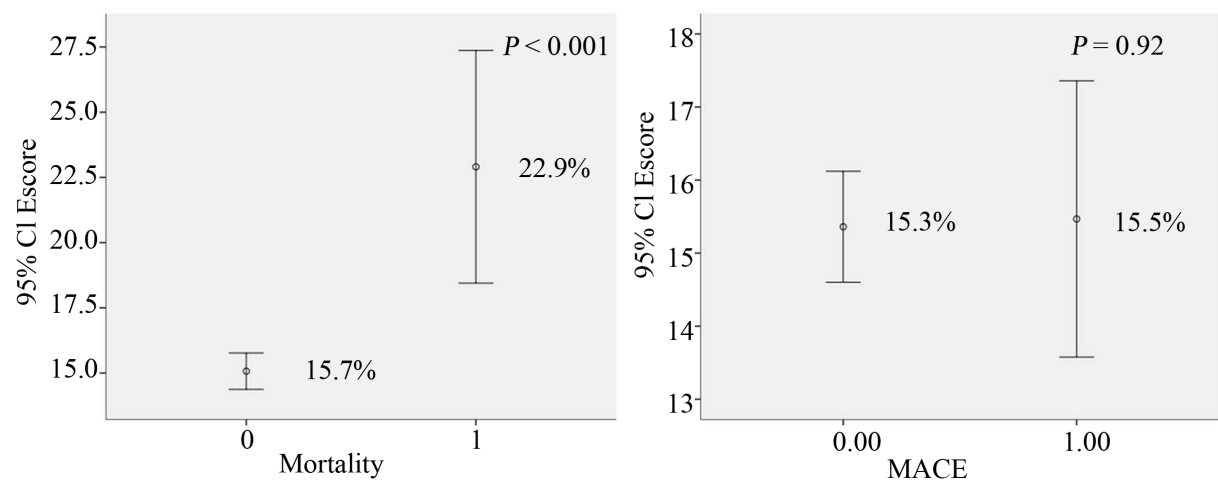

Figure 2. Results of univariate analysis of correlation between Mehran score and mortality/ MACE.
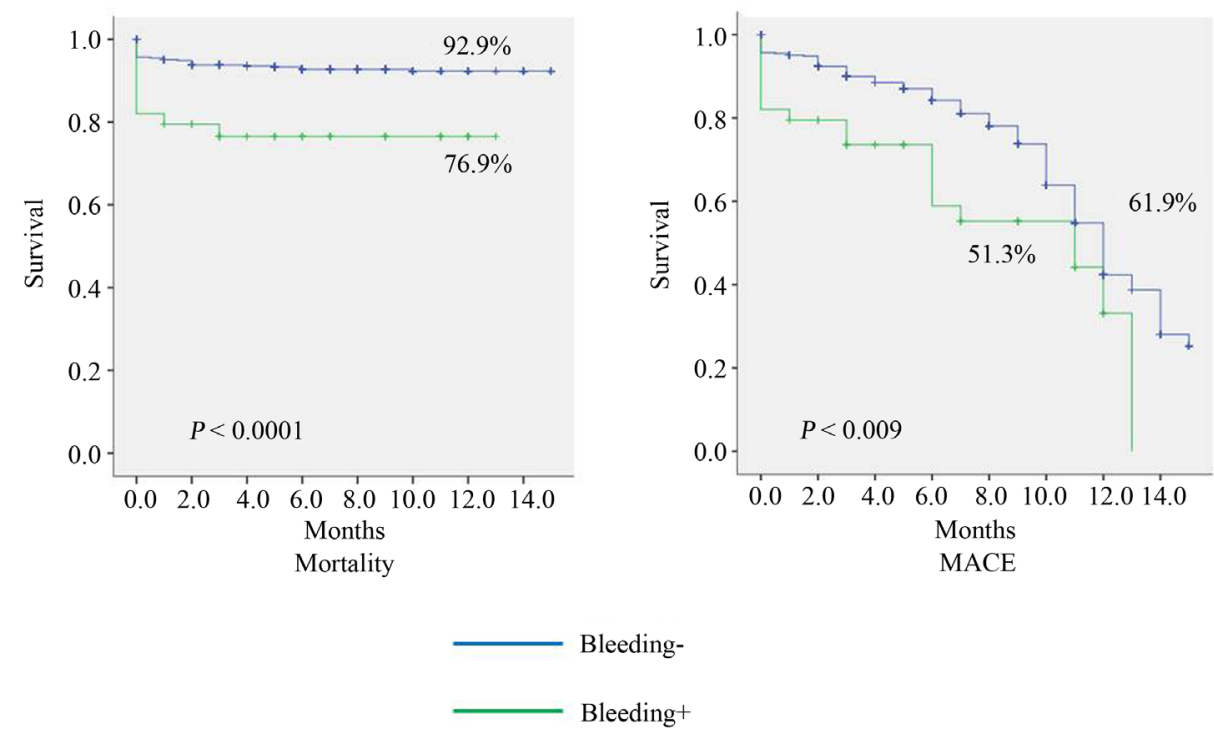

Figure 3. Results of long-term follow-up comparing patients of group I versus group II related with mortality/MACE.

Studied population showed the reality of a tertiary center. There were patients with multiple comorbidities and high prevalence of previous coronary artery disease. Groups showed significant differences in hemoglobin, left ventricle ejection fraction and statin use. Besides, group I demonstrated higher use of clopidogrel, whereas the group II used more enoxaparin, both situations associated with higher risk of bleeding [16]-[21]. Nevertheless, in multivariate analysis mortality rates were kept different.

Mechanism of MACE and bleedings in patients with ACS is not totally known. Probably, these patients have less use of adequate therapeutic [22], suspension of antiplatelet therapy, higher rates of blood transfusion [23] [24], anemia and secretion of erythropoietin [25] and activation of coagulation. It's important to highlight that the increase mortality in this group are not restrict during the hospitalization, remaining for one-year too [26].

In this context, identification of patients with high risk of bleeding is essential to planning therapeutic and intervention in ACS. International guidelines recommend use of some bleeding score like Mehran or Crusade in all patients with ACS at admission [1] [2] [13] [14].

Although didn't have studies comparing different strategies or treatment according to bleeding scores, somethings have been established like effective in diminishing incidence of bleeding. Fondaparinux has been indicated as the first choice in NSTEMI [27] [28], application of non-invasive strategies of stratification in low risk patients and correction of doses of anticoagulation and antiplatelet agents (mainly in elderly patients and whose with renal failure) [29]. Some authors suggest early invasive strategy in first four hours, with lowest exposure of 
antithrombotic and antiplatelet drugs and without complete action of that at the time of procedure [30].

Subanalysis of PLATO trial showed in 18.624 patients major bleedings in 11.6 vs. $11.2 \%(p=0.43)$, comparing ticagrelor and clopidogrel. Applying the CRUSADE bleeding model to the PLATO population of patients with non-ST-segment elevation, myocardial infarction revealed a trend towards increased non-surgical-related major bleeding in-hospital, at 30 days, and at 1 year with an increasing risk score. Patients with a very low risk score $(\leq 20)$ experienced cumulative non-surgical-related major bleeding rates of $0.5 \%, 1.0 \%$, and $2.7 \%$ in-hospital, at 30 days, and at 1 year, respectively, while those with very high risk scores $(>50)$ had rates of $3.7 \%$, $6.8 \%$, and $9.7 \%$, respectively. There were no significant CRUSADE risk score by treatment interactions [31].

Ariza-Solé et al. [32] included 1976 patients with mean age of 62.1 years in another study comparing bleeding risk scores. Almost all patients underwent angiography, $65 \%$ of them by the radial approach. The incidence of major bleeding was: CRUSADE bleeding 3.9\%; Mehran bleeding 4.8\%; ACTION bleeding 3.9\% (78/1976); and BARC $3 / 5$ bleeding 2.4\% (48/1976). Ability for predicting major bleeding was especially significant for predicting BARC $3 / 5$ bleeding (Mehran score 0.68 , CRUSADE score 0.70 and ACTION score 0.70 ). The predictive ability of CRUSADE, ACTION and Mehran scores was similar for all the definitions analyzed [32].

Choice of vascular access showed to be determinant in bleeding risk. Radial access has been considered associated with lowest rates of hemorrhagic complications [33] [34]. Use of percutaneous vascular closure devices possible have been related with lowest bleedings [35]. In this study, higher prevalence of femoral access like institution routine probably was a factor that could contribute to number of bleedings described. However, the most prevalent bleeding was intracranial hemorrhage, not directly associated with the vascular access, being relate with vascular puncture in $31 \%$ of bleedings.

Bleedings related at last seven years are decreasing, even with the higher number of interventions and available antiplatelet/anticoagulation medications. This fact suggests that physicians are more preoccupied with scores and complications [5].

\section{Limitations}

This study showed some limitations like small number of patients in bleeding group. Besides, this is an observational study and therapeutic was not change according with the bleeding risk.

\section{Conclusion}

Risk scores showed correlation with bleedings in Brazilian population. Almost half of patients with acute coronary syndromes had higher risk of bleeding, and that with major or minor bleedings had greater deaths and combined events.

\section{References}

[1] Nicolau, J.C., Timerman, A., Marin-Neto, J.A., Piegas, L.S., Barbosa, C.J.D.G., Franci, A., et al. (2014) Sociedade Diretrizes da Sociedade Brasileira de Cardiologia sobre Angina Instável e Infarto Agudo do Miocárdio sem Supradesnível do Segmento ST. Arquivos Brasileiros de Cardiologia, 102, 1-61. http://dx.doi.org/10.5935/abc.2014S001

[2] Piegas, L.S., Feitosa, G., Mattos, L.A., Nicolau, J.C., Rossi Neto, J.M., Timerman, A., et al. (2009) Diretriz da Sociedade Brasileira de Cardiologia sobre Tratamento do Infarto agudo do Miocárdio com Supradesnível do Segmento ST. Arquivos Brasileiros de Cardiologia, 93, e179-e264.

[3] Mega, J.L., Braunwald, E., Wiviott, S.D., Bassand, J.P., Bhatt, D.L., Bode, C., et al. (2012) Rivaroxaban in Patients with a Recent Acute Coronary Syndrome. The New England Journal of Medicine, 366, 9-19. http://dx.doi.org/10.1056/NEJMoa1112277

[4] Wiviott, S., Braunwald, E., McCabe, C., Montalescot, G., Ruzyllo, W., Gottlieb, S., et al. (2007) Prasugrel versus Clopidogrel in Patients with Acute Coronary Syndromes. The New England Journal of Medicine, 357, 2001-2015. http://dx.doi.org/10.1056/NEJMoa0706482

[5] Eikelboom, J.W., Mehta, S.R., Anand, S.S., Xie, C., Fox, K.A., Yusuf, S., et al. (2006) Adverse Impact of Bleeding on Prognosis in Patients with Acute Coronary Syndromes. Circulation, 114, 774-782. http://dx.doi.org/10.1161/CIRCULATIONAHA.106.612812

[6] Manoukian, S.V., Feit, F., Mehran, R., Voeltz, M.D., Ebrahimi, R., Hamon, M., et al. (2007) Impact of Major Bleeding on 30-Day Mortality and Clinical Outcomes in Patients with Acute Coronary Syndromes: An Analysis from the 
ACUITY Trial. Journal of the American College of Cardiology, 49, 1362-1368. http://dx.doi.org/10.1016/j.jacc.2007.02.027

[7] Rao, S.V., O’Grady, K., Pieper, K.S., Granger, C.B., Newby, L.K., Van de Werf, F., et al. (2005) Impact of Bleeding Severity on Clinical Outcomes among Patients with Acute Coronary Syndromes. American Journal of Cardiology, 96, 1200-1206. http://dx.doi.org/10.1016/j.amjcard.2005.06.056

[8] Kinnaird, T.D., Stabile, E., Mintz, G.S., Lee, C.W., Canos, D.A., Gevorkian, N., et al. (2003) Incidence, Predictors, and Prognostic Implications of Bleeding and Blood Transfusion Following Percutaneous Coronary Interventions. American Journal of Cardiology, 92, 930-935. http://dx.doi.org/10.1016/S0002-9149(03)00972-X

[9] Feit, F., Voeltz, M.D., Attubato, M.J., Lincoff, A.M., Chew, D.P., Bittl, J.A., et al. (2007) Predictors and Impact of Major Hemorrhage on Mortality Following Percutaneous Coronary Intervention: An Analysis of the REPLACE-2 Trial. American Journal of Cardiology, 100, 1364-1369. http://dx.doi.org/10.1016/j.amjcard.2007.06.026

[10] Ndrepepa, G., Berger, P.B., Mehilli, J., Seyfarth, M., Neumann, F.J., Schömig, A., et al. (2008) Periprocedural Bleeding and 1-Year Outcome after Percutaneous Coronary Interventions: Appropriateness of Including Bleeding as a Component of a Quadruple End Point. Journal of the American College of Cardiology, 51, 690-697. http://dx.doi.org/10.1016/j.jacc.2007.10.040

[11] Mehran, R., Pocock, S.J., Nikolsky, E., Clayton, T., Dangas, G.D., Kirtane, A.J., et al. (2010) A Risk Score to Predict Bleeding in Patients with Acute Coronary Syndromes. Journal of the American College of Cardiology, 55, 2556-2566. http://dx.doi.org/10.1016/j.jacc.2009.09.076

[12] Subherwal, S., Bach, R.G., Chen, A.Y., Gage, B.F., Rao, S.V., Newby, L.K., et al. (2009) Baseline Risk of Major Bleeding in Non-ST-Segment-Elevation Myocardial Infarction: The CRUSADE (Can Rapid Risk Stratification of Unstable Angina Patients Suppress Adverse Outcomes with Early Implementation of the ACC/AHA Guidelines) Bleeding Score. Circulation, 119, 1873-1882. http://dx.doi.org/10.1161/CIRCULATIONAHA.108.828541

[13] Hamm, C.W., Bassand, J., Agewall, S., Bax, J., Boersma, E., Bueno, H., et al. (2011) ESC Guidelines for the Management of Acute Coronary Syndromes in Patients Presenting without Persistent ST-Segment Elevation. The Task Force for the Management of Acute Coronary Syndromes (ACS) in Patients Presenting without Persistent ST-Segment Elevation of the European Society of Cardiology (ESC). European Heart Journal, 32, 2999-3054. http://dx.doi.org/10.1093/eurheartj/ehr236

[14] Jneid, H., Anderson, J.L., Wright, R.S., Adams, C.D., Bridges, C.R., Casey, D.E., et al. (2012) ACCF/AHA Focused Update of the Guideline for the Management of Patients with Unstable Angina/Non ST-Elevation Myocardial Infarction (Updating the 2007 Guideline and Replacing the 2011 Focused Update): A Report of the American College of Cardiology Foundation/American Heart Association Task Force on Practice Guidelines. Circulation, 126, 875-910. http://dx.doi.org/10.1161/CIR.0b013e318256f1e0

[15] Mehran, R., Rao, S.V., Bahht, D.L., Gibson, M., Caixeta, A., Eikelboom, J., et al. (2011) Standardized Bleeding Definitions for Cardiovascular Clinical Trials. A Consensus Report from the Bleeding Academic Research Consortium. Circulation, 123, 2736-2747. http://dx.doi.org/10.1161/CIRCULATIONAHA.110.009449

[16] Nikolsky, E., Mehran, R., Dangas, G., Fahy, M., Na, Y., Pocock, S.J., et al. (2007) Development and Validation of a Prognostic Risk Score for Major Bleeding in Patients Undergoing Percutaneous Coronary Intervention via the Femoral Approach. European Heart Journal, 28, 1936-1945. http://dx.doi.org/10.1093/eurheartj/ehm194

[17] Stone, G.W., Witzenbichler, B., Guagliumi, G., Peruga, J.Z., Brodie, B.R., Dudek, D., et al. (2008) Bivalirudin during Primary PCI in Acute Myocardial Infarction. New England Journal of Medicine, 358, 2218-2230. http://dx.doi.org/10.1056/NEJMoa0708191

[18] Moscucci, M., Fox, K.A., Cannon, C.P., Klein, W., Lopez-Sendon, J., Montalescot, G., et al. (2003) Predictors of Major Bleeding in Acute Coronary Syndromes: The Global Registry of Acute Coronary Events (GRACE). European Heart Journal, 24, 1815-1823. http://dx.doi.org/10.1016/S0195-668X(03)00485-8

[19] Fox, C.S., Muntner, P., Chen, A.Y., Alexander, K.P., Roe, M.T., Cannon, C.P., et al. (2010) Use of Evidence-Based Therapies in Short-Term Outcomes of ST-Segment Elevation Myocardial Infarction and Non-ST-Segment Elevation Myocardial Infarction in Patients with Chronic Kidney Disease: A Report from the National Cardiovascular Data Acute Coronary Treatment and Intervention Outcomes Network registry. Circulation, 121, 357-365. http://dx.doi.org/10.1161/CIRCULATIONAHA.109.865352

[20] Hanna, E.B., Chen, A.Y., Roe, M.T., Funk, M. and Saucedo, J.F. (2011) Characteristics and In-Hospital Outcomes of Patients with Non-ST-Segment Elevation Myocardial Infarction and Chronic Kidney Disease Undergoing Percutaneous Coronary Intervention. JACC: Cardiovascular Interventions, 4, 1002-1008. http://dx.doi.org/10.1016/j.jcin.2011.05.022

[21] Yusuf, S., Zhao, F., Mehta, S.R., Chrolavicius, S., Tognoni, G. and Fox, K.K. (2001) Effects of Clopidogrel in Addition to Aspirin in Patients with Acute Coronary Syndromes without ST-Segment Elevation. New England Journal of Medicine, 345, 494-502. http://dx.doi.org/10.1056/NEJMoa010746 
[22] Wang, T.Y., Xiao, L., Alexander, K.P., Rao, S.V., Kosiborod, M.N., Rumsfeld, J.S., et al. (2008) Antiplatelet Therapy Use after Discharge among Acute Myocardial Infarction Patients with In-Hospital Bleeding. Circulation, 118, 21392145. http://dx.doi.org/10.1161/CIRCULATIONAHA.108.787143

[23] Dietrich, K.A., Conrad, S.A., Hebert, C.A., Levy, G.L. and Romero, M.D. (1990) Cardiovascular and Metabolic Response to Red Blood Cell Transfusion in Critically Ill Volume-Resuscitated Nonsurgical Patients. Critical Care Medicine, 18, 940-944. http://dx.doi.org/10.1097/00003246-199009000-00007

[24] Rao, S.V., Jollis, J.G., Harrington, R.A., Granger, C.B., Newby, L.K., Armstrong, P.W., et al. (2004) Relationship of Blood Transfusion and Clinical Outcomes in Patients with Acute Coronary Syndromes. JAMA, 292, 1555-1562. http://dx.doi.org/10.1001/jama.292.13.1555

[25] Smith, K.J., Bleyer, A.J., Little, W.C. and Sane, D.C. (2003) The Cardiovascular Effects of Erythropoietin. Cardiovascular Research, 59, 538-548. http://dx.doi.org/10.1016/S0008-6363(03)00468-1

[26] Mehran, R., Pocock, S.J., Stone, G.W., Clayton, T.C., Dangas, G.D., Feit, F., et al. (2009) Associations of Major Bleeding and Myocardial Infarction with the Incidence and Timing of Mortality in Patients Presenting with Non-STElevation Acute Coronary Syndromes: A Risk Model from the ACUITY Trial. European Heart Journal, 30, 14571466. http://dx.doi.org/10.1093/eurheartj/ehp110

[27] Yusuf, S., Mehta, S.R., Chrolavicius, S., Afzal, R., Pogue, J., Granger, C.B., et al. (2006) Comparison of Fondaparinux and Enoxaparin in Acute Coronary Syndromes. New England Journal of Medicine, 354, 1464-1476. http://dx.doi.org/10.1056/NEJMoa055443

[28] Steg, P.G., Jolly, S.S., Mehta, S.R., Afzal, R., Xavier, D., Rupprecht, H.J., et al. (2010) Low-Dose vs. Standard-Dose Unfractionated Heparin for Percutaneous Coronary Intervention in Acute Coronary Syndromes Treated with Fondaparinux: The FUTURA/OASIS-8 Randomized Trial. JAMA, 304, 1339-1349. http://dx.doi.org/10.1001/jama.2010.1320

[29] Alexander, K.P., Chen, A.Y., Roe, M.T., Newby, L.K., Gibson, C.M., Allen-LaPointe, N.M., et al. (2005) Excess Dosing of Antiplatelet and Antithrombin Agents in the Treatment of Non-ST-Segment Elevation Acute Coronary Syndromes. JAMA, 294, 3108-3116. http://dx.doi.org/10.1001/jama.294.24.3108

[30] Ariza-Solé, A., Salazar-Mendiguchía, J., Lorente, V., Sánchez-Salado, J.C., Romaguera, R., Ferreiro, J.L., et al. (2015) Predictive Ability of Bleeding Risk Scores in the Routine Clinical Practice. European Heart Journal: Acute Cardiovascular Care, 4, 3205-3210.

[31] Becker, R.C., Bassand, J.P., Budaj, A., Wojdyla, D.M., James, S.K., Cornel, J.H., et al. (2011) Bleeding Complications with the P2Y12 Receptor Antagonists Clopidogrel and Ticagrelor in the PLATelet Inhibition and Patient Outcomes (PLATO) Trial. European Heart Journal, 32, 2933-2944. http://dx.doi.org/10.1093/eurheartj/ehr422

[32] Ariza-Solé, A., Salazar-Mendiguchía, J., Lorente, V., Sánchez-Salado, J.C., Romaguera, R., Ferreiro, J.L., et al. (2015) Predictive Ability of Bleeding Risk Scores in the Routine Clinical Practice. European Heart Journal: Acute Cardiovascular Care, 4, 205-210. http://dx.doi.org/10.1177/2048872614538405

[33] Hamon, M., Rasmussen, L.H., Manoukian, S.V., Cequier, A., Lincoff, M.A., Rupprecht, H.J., et al. (2009) Choice of Arterial Access Site and Outcomes in Patients with Acute Coronary Syndromes Managed with an Early Invasive Strategy: The ACUITY Trial. EuroIntervention, 5, 115-120. http://dx.doi.org/10.4244/EIJV5I1A18

[34] Jolly, S.S., Amlani, S., Hamon, M., Yusuf, S. and Mehta, S.R. (2009) Radial versus Femoral Access for Coronary Angiography or Intervention and the Impact on Major Bleeding and Ischemic Events: A Systematic Review and MetaAnalysis of Randomized Trials. American Heart Journal, 157, 132-140. http://dx.doi.org/10.1016/j.ahj.2008.08.023

[35] Sanborn, T.A., Ebrahimi, R., Manoukian, S.V., McLaurin, B.T., Cox, D.A., Feit, F., et al. (2010) Impact of Femoral Vascular Closure Devices and Antithrombotic Therapy on Access Site Bleeding in Acute Coronary Syndromes: The Acute Catheterization and Urgent Intervention Triage Strategy (ACUITY) Trial. Circulation: Cardiovascular Interventions, 3, 57-62. http://dx.doi.org/10.1161/CIRCINTERVENTIONS.109.896704 